\title{
Recortes de intensas trajetórias
}

\author{
Rosana Morgado*
}

Escrever um texto em homenagem à Suely Souza de Almeida é uma honra e um privilégio. Debruçar-me de forma sistemática, sobre a trajetória da pesquisadora, professora, gestora e militante dos campos temáticos: violência de gênero e políticas públicas; violência estatal e lutas sociais; e direitos humanos e práticas sociais, todos com claros pontos de interseção, significa revisitar também minha própria história profissional e pessoal. Tive a oportunidade de acompanhar em 2005 seu concurso para Profa. Titular na Escola de Serviço Social da UFRJ e ao ser convidada para escrever este artigo, utilizei como referência o Memorial por ela apresentado. Considerei assim, que ninguém melhor do que a própria Suely, para falar de sua trajetória.

Para Suely escrever um memorial remete ao desafio de contar uma história, que é, ao mesmo tempo, singular e coletiva e, dessa forma, percorrer os territórios da memória; implica deslocar-se em temporalidades distintas. Apoiada em Hobsbawm destaca que, o passado é uma dimensão permanente da consciência humana, cujo sentido é um desafio analisar, sendo necessário localizar suas mudanças e transformações ${ }^{1}$.

Ainda segundo Suely, referenciada em Maurice Halbwachs, contar tal história supõe um exercício de memória, cuja característica é ter, também, uma função coletiva. Cada memória individual é um ponto de vista sobre a memória coletiva, o qual guarda estreita relação com o lugar ocupado pelo sujeito. Este lugar, por sua vez, se altera segundo as relações que são mantidas com outros meios. Trata-se, pois, de uma memória, que, cons-

\footnotetext{
"Doutora em Ciências Sociais pela Pontifícia Universidade Católica de São Paulo (2001). Pós-Doutorado pela University of Hertfordshire, Inglaterra (2010). Atualmente é Diretora Adjunta do Programa de Pós- Graduação em Serviço Social da Universidade Federal do Rio de Janeiro e pesquisadora do NETIJ - Núcleo de Estudos e Trabalhos sobre Família, Infância e Juventude. Correspondência: Av Pasteur, 250, fundos - Escola de Serviço Social/UFRJ. Praia vermelha, Urca - Rio de Janeriro/RJ. CEP 22290-240. Email: <rmorgadopaiva@hotmail.com>

${ }^{1} \mathrm{O}$ recurso ao formato itálico quando da utilização de passagens extraídas do memorial, me pareceu mais adequado do que a utilização formal de citações. Isto por que não são citações no estrito senso de um artigo acadêmico, mas sim, minha leitura e também revisitação a uma trajetória que em grande parte acompanhei e que em diversos momentos estive implicada.
} 
tituída de modo singular, não deixa de ser, simultaneamente, coletiva, construída em um quadro econômico, político e cultural determinado, na relação com outros sujeitos.

Suely, carioca, filha única, nascida em 1956, casou-se e teve duas filhas, fez a graduação e o mestrado em Serviço Social na UFRJ, terminandoos respectivamente em 1977 e em 1986. Defendeu sua dissertação de mestrado, sob orientação de Moema Toscano, com o título: Violência contra a mulher: determinações de classe e cultura. O doutorado em Ciências Sociais foi concluído em 1996, na Pontifícia Universidade Católica de São Paulo, sob a orientação de Heleieth Saffioti, relacionamento acadêmico e pessoal, estreitado pela participação de Heleieth como membro efetivo em sua banca de mestrado, marcando assim a consolidação da escolha de seu tema de investigação/intervenção político/acadêmica. Ao longo do doutorado, a realização de dois anos de período sanduíche no Centre National de la Recherche Scientifique, no então - GEDISST - Groupe d' Études sur la Division Socialle et Sexuelle du Travail, sob a orientação de Danièle Kergöat, propiciou os insumos necessários para a apresentação de sua tese intitulada: Violência de gênero: público $X$ privado, posteriormente publicada em livro (1998) com o título: Femicídio: algemas (in) visíveis do público-privado.

Suely pontua sua trajetória, relacionando-a à conjuntura do país: uma jovem estudante de Serviço Social, que ingressou na Universidade Federal do Rio de Janeiro em 1974, aos 17 anos de idade, ainda em pleno período de "caça às bruxas", viveu a luta pela democratização do país e da própria universidade; foi maturando cada período da sua trajetória profissional e acadêmica, sem procurar saltar etapas; trabalhou como Assistente Social; tornou-se docente na área; fez a primeira etapa de seus estudos pós-graduados em Serviço Social; tornou-se feminista; foi, gradativamente, se afastando do estrito debate profissional, sem jamais renunciar à centralidade da formação de assistentes sociais, de pesquisadores (as) e de equipes interdisciplinares; desenvolveu e aprofundou estudos em violência e relações de gênero; doutorou-se em Ciências Sociais; teve suas atividades acadêmicas regulares interrompidas por dois períodos de ano e meio cada - um, por decisão própria, para complementar seus estudos doutorais na França, e outro, involuntariamente, para tratar da saúde - e, hoje, faz o caminho de volta ao Serviço Social - conquanto enfatizando ainda mais o diálogo interdisciplinar - pela porta da pesquisa sobre Direitos Humanos, sem abandonar os temas precedentes; hoje, aos 49 anos de idade, estando prestes a completar 28 anos de graduada e 21 anos como docente desta Escola, decidiu fazer um concurso para a vaga de Professor Titular.

O Memorial apresentado por Suely foi divido em quatro partes distintas embora profundamente interligadas: Formação Acadêmica, Trajetória Acadêmica, Gestão Acadêmica e Projeto Acadêmico. Em cada um desses eixos procuro evidenciar minha inserção na vida acadêmica e nos contextos institucional e histórico, mostrando os campos de possibilidades 
que vão sendo construídos, as relações que vou tecendo, as escolhas que vou fazendo e as suas implicações na minha trajetória acadêmica.

Para este artigo, em número de páginas delimitadas, fundi os dois primeiros em apenas um eixo, menos para destacar os aspectos datados e mais para publicizar sua forma de compreender como esses fatos singulares se articulam e ganham significado em um projeto que tem indiscutivelmente sua marca individual, mas que, contextualizada historicamente, têm também uma perspectiva coletiva.

\section{Formação e Trajetória Acadêmica}

Segundo Suely: minha trajetória acadêmica foi sendo construída gradualmente, num entrecruzamento de tempos distintos: um tempo de buscas, conflitos, descobertas, desenredos; um tempo de afirmação de projetos, de um estilo profissional inquieto, de alargamento de fronteiras, de rupturas e de construção de pontes. São temporalidades que se conjugam, se encontram, por vezes, se opõem e, não raro, se sobrepõem. Não falo de um tempo linear, mas de percursos que têm me permitido maturar uma concepção de mundo e construir lugares: profissional, acadêmico e político.

Para Suely um dos aspectos mais importantes a destacar refere-se ao fato de que boa parte de sua formação inicial ocorreu em condições históricas extremamente adversas - dos 17 anos cursados de educação básica e educação superior, 15 o foram durante a ditadura militar, o que, seguramente, representou perdas imensuráveis. A reflexão sobre a minha formação acadêmica não pode prescindir, portanto, de uma referência à geração pós-68, entendendo geração a partir de vivências de acontecimentos comuns, ou seja, da inserção do sujeito na história, e não, simplesmente, com base em critério etário. Tendo por referência Karl Mannheim, como também as contribuições de Jean-Pierre Azéma, Alzira Alves de Abreu destaca que: "Cada geração se define por um acontecimento ou uma série de acontecimentos que tem um caráter único e fundador, acontecimentos que estruturam uma época, que dão aos que a viveram uma representação mental e determinam comportamentos específicos, práticas políticas, sociais e culturais. Um acontecimento atinge todos os indivíduos, logo todas as gerações, mas a forma e a intensidade serão diferenciadas em relação a cada indivíduo" ${ }^{\prime 2}$. Pretendo, assim, refletir sobre como, integrando uma juventude que se constituiu e se reconheceu como tal, no quadro do terrorismo de Estado intensificado nos anos de chumbo, a minha formação acadêmica foi se processando. Isto é, trata-se de mapear brevemente as condições históricas que constituíram o solo a partir do qual o meu projeto

${ }^{2}$ Cf. ABREU, Alzira Alves. "Quando eles eram jovens revolucionários". In: VIANNA, H (org.). Galeras cariocas: territórios de conflitos e encontros culturais. $2^{\text {a }}$ edição. Rio de Janeiro, Editora UFRJ, 2003. 
profissional foi se delineando, a minha concepção de mundo foi se forjando e as minhas relações foram se constituindo. Longe de uma visão determinista, quero mostrar o campo de possibilidades que fui identificando e como as minhas escolhas foram se efetivando. Ingressei na Universidade Federal do Rio de Janeiro (UFRJ) em março de 1974, para cursar Serviço Social, minha primeira opção no vestibular unificado. (...) a decisão foi tomada, na verdade, de forma bem intuitiva, mas, provavelmente, não aleatória. Creio que havia um sentimento difuso de sede de justiça e de intenção de concretizar um engajamento com as classes populares. Penso que tive, efetivamente, uma forte socialização com base em princípios cristãos e, ademais, segundo a perspectiva hegemônica de gênero. Nada melhor, portanto, do que uma escolha profissional que mesclasse educação, assistência e intenção de justiça. Minha graduação foi toda realizada durante o Governo do Presidente Ernesto Geisel. Apesar do "projeto liberalizante" anunciado por Geisel e do seu propalado projeto político de "distensão lenta, gradual e segura", num quadro de esgotamento do "milagre brasileiro", e de sinais de resistência que iam se mostrando, inclusive, em processos institucionais, como nos embates legislativos de 1974, os órgãos de segurança continuaram atuando intensamente, reprimindo as organizações clandestinas, com a realização de centenas de prisões, assim como denúncias de desaparecimentos e assassinatos de mais de duas dezenas de militantes políticos nos dois primeiros anos de governo. No último ano do curso, o "Pacote de Abril" foi lançado, levando ao recesso do Congresso, à extensão da "Lei Falcão", que censurava o debate político-eleitoral, à decretação da reforma do Judiciário, à ampliação do mandato presidencial para seis anos, dentre outras medidas. A retirada da censura prévia a órgãos da grande imprensa, como o Estado de São Paulo, dois anos antes, e, posteriormente, da imprensa alternativa, como o Opinião, o Pasquim e o Movimento, permitia acompanhar mais atentamente o movimento de resistência que ia se intensificando e as lutas que iam sendo travadas, sobretudo pela anistia, no âmbito da sociedade civil. Quando cursei Serviço Social, a universidade vivia a tensão entre esse enorme aparato de repressão e a retomada da organização do movimento estudantil, embora de forma ainda bastante embrionária. Na Universidade de Brasília (UnB), ocorreram os maiores confrontos, tendo sido o campus universitário ocupado por tropas militares, a pedido do Reitor. Esse processo de reorganização foi ganhando maior vitalidade em 1976 e se fortalecendo em 1977. Participei, na UFRJ, das primeiras assembléias para retomada do movimento estudantil, sob o olhar vigilante das forças de repressão. Infelizmente, terminei o curso sem ver esse processo ser levado a cabo. A formação das(os) Assistentes Sociais tinha, indubitavelmente, orientação positivista e um reforço à vocação humanistacristã do Serviço Social. O ensino de graduação passou ao largo das inquietações, polêmicas e da literatura derivada do "Movimento de Reconceituação do Serviço Social na América Latina", que abalava as bases 
teóricas e políticas da profissão no Cone Sul. A segunda onda do movimento feminista - e o início da "Década Internacional da Mulher" - não encontrou, naquele momento, qualquer eco em uma profissão tão marcadamente feminina. Em outras palavras, o insulamento do Serviço Social da UFRJ, nesse período, subtraiu dos alunos a possibilidade de apreensão de um referencial teórico crítico, que Ihes permitisse a análise da realidade brasileira, das políticas sociais, dos campos de intervenção profissional e dos sujeitos usuários dos serviços sociais.

O interregno entre a conclusão do curso de Serviço Social e a do Doutorado em Ciências Sociais foi de dezenove anos. E esta foi uma decisão consciente. Queria exercer a profissão, viver os seus inúmeros e imensos desafios, antes de voltar aos bancos escolares. Não desejava ter uma formação exclusivamente teórica em uma profissão que é eminentemente interventiva. $\mathrm{O}$ trabalho docente supõe a formação de profissionais para o exercício profissional - a redundância, neste caso, é necessária -, com sólida base teórica. Tampouco tinha a expectativa de exercer a profissão sem continuar a desenvolver estudos teóricos.

Nesta direção, a realização do curso de Aperfeiçoamento em Serviço Social entre 1980 e 1981, foi concomitante ao trabalho que desenvolvia na Associação Cristã de Moços (ACM), com funções de coordenação de uma grande equipe interdisciplinar e de supervisão a alunos de Serviço Social que faziam estágio na instituição. Minhas preocupações políticas e pedagógicas levaram-me a "devorar" toda uma literatura de Educação Popular à qual tinha acesso. Passei a estudar, em conjunto com a equipe interdisciplinar que dirigia, toda a obra de Paulo Freire e de outros autores no campo da educação popular, como Carlos Rodrigues Brandão, Moacir Gadotti, Moacyr de Góes, Pedro Garcia, Osmar Fávero, Aída Bezerra e outros. Tematizávamos questões como relações de poder x solidariedade nas camadas populares, saber x poder popular, violência e formas de sociabilidade, populismo pedagógico (aparelhamento/cooptação de movimentos populares) $x$ autonomia popular, lutas específicas $x$ lutas gerais, interlocução movimentos populares x poder público (estratégias e táticas).

E a Escola de Serviço Social da UFRJ? Encontrei uma unidade acadêmica distinta daquela que havia deixado em 1977, num país com uma conjuntura política também bastante modificada. O Al-5 fora extinto em 1978, o multipartidarismo havia sido restabelecido. A grande novidade político-partidária do momento - o Partido dos Trabalhadores - havia sido criada, e a Lei da Anistia, promulgada em 1979, trouxera de volta ao país importantes e históricas lideranças políticas. Não obstante, atentados terroristas ainda aconteciam, como o assassinato de Lida Monteiro, secretária da $O A B$, em 1980, e as bombas do Riocentro, em 1981. Sucessivas greves aconteciam a partir de 1978 , especialmente na região do $A B C$ paulista. $O$ movimento estudantil retomava fôlego. A Diretora Pro-Tempore era a Professora Maria Augusta Temponi, nomeada pelo então Reitor Adolpho Polillo, 
que assumira o seu mandato em setembro de 1981, permanecendo na direção da UFRJ até agosto de 1985.

O ingresso no curso de mestrado ocorreu no início de 1981. Embora tenha sido classificada em $1^{\circ}$ lugar, nunca recebeu bolsa, o que a impediu de ter dedicação exclusiva ao curso. Fiz todo o mestrado realizando atividades profissionais regulares. Aliás, a partir desse momento, passou a haver uma sobreposição constante entre a minha formação acadêmica e a minha trajetória profissional. Só nesse momento, pude estudar, de forma mais sistemática e orientada, autores como Gramsci, Marx, Hegel, e os marxistas brasileiros, como Carlos Nelson Coutinho, Leandro Konder, Florestan Fernandes, Octavio lanni. Também nessa fase foi possível me apropriar da vasta literatura que vinha sendo produzida no Serviço Social: Marilda lamamoto, José Paulo Netto, Vicente Faleiros, Maria Helena Lima, Josefa Batista Lopes, Safira Ammann, Alba Carvalho, além da socióloga Miriam Limoeiro, que influenciou toda uma geração de assistentes sociais. Até então, eu tinha acesso a essa literatura, por iniciativa própria, e a discutia nos pequenos grupos e círculos de leitura que constituía no âmbito do trabalho profissional, em geral, com a participação dos alunos supervisionados.

No primeiro ano de realização do Curso de Mestrado, Suely tomou conhecimento da abertura de processo seletivo para o projeto experimental "Implantação de Serviço Social em Delegacias Policiais do Rio de Janeiro", a partir de convênio entre a UFRJ, por meio da Escola de Serviço Social, e o Governo do Estado do Rio de Janeiro, por intermédio da Secretaria de Segurança Pública. Participei da seleção e fui contratada para participar da experiência, o que provocou protestos veementes de uma professora da ESS/UFRJ, que tomara conhecimento do trabalho que eu coordenava na ACM e da demissão coletiva da equipe. A professora em questão não entendia como uma "comunista", "subversiva" poderia trabalhar em uma delegacia policial. Malgrado o seu protesto, fui uma das três Assistentes Sociais contratadas pela Fundação Universitária José Bonifácio, vinculada à UFRJ.

Fui aprovada juntamente com as assistentes sociais Maria Elena Ruschell Cançado e Marlise Vinagre Silva. Cada uma de nós ficou responsável pela implantação do Serviço Social em uma delegacia policial: eu fui localizada na Delegacia de Campinho (28 $\left.{ }^{\mathrm{a}} \mathrm{DP}\right)$, Maria Elena, na Delegacia de Duque de Caxias (59 $\mathrm{DP}$ ) e Marlise, na Delegacia de Botafogo (10 $\left.{ }^{\mathrm{a}} \mathrm{DP}\right)$. Ficamos subordinadas tecnicamente à Coordenadora do Projeto e então Diretora da ESS/UFRJ, Professora Maria Augusta Temponi.

O Estado do Rio de Janeiro era governado por Chagas Freitas, desde 1979, tendo chegado ao cargo por via indireta e nele permanecido até 1983. Seu Secretário de Segurança era um general. Eu tinha acabado de completar 25 anos e era a única Assistente Social daquela delegacia e, aliás, a primeira. O ambiente me era completamente inóspito. Paradoxos diversos, novos desafios e, até mesmo, alguns pontos de contato entre ex- 


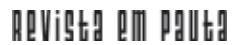

\} RECORTES DE INTENSAS TRAJETÓRIAS - MORGADO, R. \}

DOI: $10.12957 /$ REP.2016.27869

periências tão diferentes se me apresentaram. Alguns dos paradoxos: embora exercesse atividades profissionais na instituição policial, não pertencia aos seus quadros; portanto, deveria escapar ao enquadramento hierárquico institucional e, ao mesmo tempo, aprender a lidar com este; representava um dos agentes de mediação institucional para a população, mas era imperativo que eu me distinguisse radicalmente dos seus demais agentes; minha concepção ético-política era essencialmente antitética à da instituição que emoldurava minha prática; tratava-se de uma instituição extremamente hostil a mim, como cidadã e, certamente, às organizações e movimentos populares, com os quais eu buscava estabelecer elos, a partir dessa mesma instituição.

Eis alguns desafios: conhecer "por dentro" formas de sociabilidade impostas aos seus agentes, práticas extralegais, regras de solidariedade corporativas etc.; conferir a esse conhecimento dois significados: a produção acadêmica e o apoio às demandas da população usuária; enfrentar as relações de poder institucionais, com competência técnico-política e em articulação com instituições acadêmicas (por exemplo, a própria UFRJ e Escritórios Modelos de diversas universidades), com organizações de defesa dos direitos humanos (tais como Ordem dos Advogados do Brasil e Associação Brasileira de Imprensa), com organizações não-governamentais (dentre as quais, o IDAC - Instituto de Ação Cultural e o ISER - Instituto de Estudos da Religião), como também com movimentos sociais e organizações locais, visando à divulgação da experiência e ao estabelecimento de intercâmbios diversos.

Os pontos de contato: a urgência do aprendizado para lidar com sólidas relações de poder, com mecanismos de controle e repressão, e a implantação do Serviço Social em um vasto campo totalmente inexplorado.

As áreas de competência do Serviço Social ("problemas sociais de natureza não-criminológica") e da Polícia Civil ("problemas criminológicos"), inicialmente delimitadas por meio do convênio, foram sendo redefinidas e renegociadas na prática. Entendia que o atendimento prestado pelo Serviço Social não deveria ficar restrito às situações triadas pela polícia, que faz o plantão. Seria necessário conhecer as demandas globais, para então circunscrever sua área de intervenção. Para tanto, a equipe - composta por mim e por estagiários de Serviço Social - deveria ter penetração na unidade policial, circular por seus setores, observar os plantões. Somente dessa forma foi possível definir, em reuniões com delegados e chefes das seções, qual seria o objeto de intervenção do Serviço, rompendo a barreira entre o "criminológico" e o "não-criminológico".

Implantei um projeto de atendimento a familiares de detentos (formalmente proibido pelo convênio), o que me possibilitou, além de prestar atendimento técnico a esse segmento, o conhecimento de formas de interconexão entre os mundos da criminalidade e da polícia (seus códigos, habitus, relações de disputa e solidariedade, linguagem etc) e com os problemas do judiciário. 


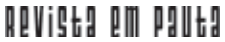

\} RECORTES DE INTENSAS TRAJETÓRIAS - MORGADO, R. \}

DOI: $10.12957 /$ REP.2016.27869

A violência doméstica merece um destaque especial, por ter se tornado objeto de intervenção sistemática do Serviço Social na instituição. $\mathrm{Na}$ época, não existiam delegacias especializadas no atendimento à mulher, centros de referência, nem casas-abrigo. Tratava-se de um problema naturalizado e banalizado socialmente - características que ainda se mantêm -, que não gozava de estatuto relevante na unidade policial; ao contrário, a vítima do sexo feminino ficava exposta à sobreviolência institucional.

O Serviço Social tinha o desafio de apoiar a demanda da denunciante, fortalecer o seu poder de negociação, reforçar sua auto-estima, desvendar mecanismos burocráticos que dificultavam o processamento da queixa e, ainda, refletir sobre o caráter coletivo de um problema aparentemente apenas pessoal. Era fundamental, entretanto, que essa forma de mediação não resvalasse para a "solidariedade vitimista" - concepção presente não só em movimentos feministas, mas também em estudos sobre mulher. Esse problema passou a constituir para mim um desafio teórico, revelando, de forma incisiva, os entrecruzamentos entre relações contraditórias de gênero, de classe e raciais, e sua potenciação, ao serem enquadradas em um dos braços armados do Estado.

Eis assim um salto gigantesco: de uma rica experiência em Educação Popular passei para o interior de um aparelho repressivo do Estado, devidamente escoltada pela Universidade. Essa experiência foi importante para a minha formação acadêmica, pelo menos em dois níveis. O primeiro diz respeito à participação sistemática que eu e as duas outras colegas tivemos na disciplina curricular obrigatória "Metodologia Aplicada", co-requisito ao estágio curricular, e na qual estava inscrito o conjunto dos alunos estagiários das delegacias. (...) O segundo nível diz respeito à descoberta que fiz sobre a extensão e a gravidade da violência doméstica praticada contra mulheres, assim como a violência institucional, exercida por agentes do Estado, em larga escala, que aguça e potencializa a primeira. Passei a me dedicar ao estudo do tema e não mais me desliguei desse campo de pesquisa, ainda que o tenha tentado algumas vezes. Este foi um extraordinário processo formativo. Aproximei-me de grupos de pesquisa nessa área, participei de seminários e debates diversos, fiz palestras e conferências, fui a encontros feministas e descobri uma outra literatura. Relatos biográficos pungentes, como o de Domitila, em Se me deixam falar..., reconstituído por Moema Viezzer; textos teóricos densos, como A Mulher e a sociedade de classes, de Heleieth Saffioti e O Segundo Sexo, de Simone de Beauvoir; pesquisas brasileiras instigantes, como as de Rose-Marie Muraro, Felicia Madeira e Paul Singer, Cristina Bruschini e outras. Desse campo extraí o objeto de investigação da minha dissertação de mestrado e, a partir de então, comecei a delinear, de forma mais nítida, um perfil de pesquisadora. Desvinculei-me do trabalho nas Delegacias Policiais quando fui chamada para assumir o cargo de Assistente Social do Instituto Nacional de Assistência Médica da Previdência Social (INAMPS), para o qual fora aprovada em 
concurso público. Não me desvincularia, contudo, desse trabalho na qualidade de pesquisadora, uma vez que desejava - e, de fato, o fiz - concluir pesquisa para elaboração de dissertação de mestrado.

De 1982 a 1984, portanto, trabalhou simultaneamente no INAMPS, em Irajá, e na Universidade Federal Fluminense, em Niterói, como também cursava créditos do mestrado, na Praia Vermelha. De 1984 a 1986, trabalhou como docente na UFF e na UFRJ, e fazia a dissertação de mestrado. As duas unidades de ensino vivam conflitos permanentes e momentos de grande tensão, decorrentes do choque de concepções teóricas e políticas, sem que se conseguisse travar um debate aberto e plural.

Para ela, o Doutorado foi menos acidentado do que o Mestrado, posto que fui admitida no então Programa Institucional de Capacitação Docente (PICD) da CAPES, tendo obtido afastamento integral das minhas atividades docentes, o que me permitiu realizar o curso em quatro anos. Desde então, passei a coordenar projetos de pesquisa, com a participação das professoras Maria Elena Cançado e Marlise Vinagre Silva, que ingressaram na UFRJ em concursos posteriores, e de Heleieth Saffioti, na qualidade de assessora. Tinha, nas viagens interestaduais e nessas práticas essencialmente femininas, a companhia da minha grande amiga e companheira de trabalho Maria Elena Cançado, que iniciara também os seus estudos doutorais, na condição de ouvinte. Infelizmente, nesse mesmo ano, sofri um grande golpe, com a perda precoce da minha amiga, e as viagens tornaramse extremamente penosas.

Sobre a UFRJ Suely mais uma vez destaca: ingressei na Escola de Serviço Social da UFRJ por concurso público, no qual se inscreveram cerca de 30 candidatos para vaga única. A Escola de Serviço Social passava por grandes divergências internas. O debate acadêmico encontrava-se inteiramente subsumido às disputas ideológicas. O movimento estudantil era extremamente atuante, constituindo-se em um dos atores em relevo nesse cenário. As reuniões departamentais eram verdadeiras assembléias de professores e alunos. O Departamento de Métodos e Técnicas, no qual fiquei lotada, vivia embates diários com os dois outros departamentos e com a direção da Escola. Tentava-se a recomposição das forças presentes nessa unidade de ensino, com a redistribuição dos seus membros entre os três Departamentos, gerada por um movimento próprio dos professores insatisfeitos. A gestão superior da Universidade ocorria em moldes tradicionais, ainda sob a direção do Professor Adolpho Polillo. Não havia a UFRJ experimentado eleições dos dirigentes e democratização dos seus fóruns deliberativos. A Escola de Serviço Social, embalada pelos ecos das "Diretas Já", tentava fazer tais experiências no seu próprio âmbito, o que ocorria por meio de disputas acirradas, ásperas, por vezes sem mediações internas, resvalando os conflitos para as instâncias superiores da Universidade. 


\section{Revistg aाm paltg}

\} RECORTES DE INTENSAS TRAJETÓRIAS - MORGADO, R. \}

DOI: $10.12957 /$ REP.2016.27869

Até 1996, quando concluí o doutorado, atuei, em nível de docência, exclusivamente na graduação. A partir de 1997, ministrei também cursos na pós-graduação. Ao longo dos 21 anos de docência na ESS/UFRJ, assumi, dentre outras, as disciplinas de "Relações de Gênero e Serviço Social" e "Direitos Humanos no Brasil" na graduação. Com a reforma curricular de 1992, foi introduzida a disciplina optativa "Relações de Gênero", fruto do debate que vínhamos acumulando na ESS/UFRJ, a partir de pesquisas desenvolvidas sobre o tema e aglutinadas no GECEM - Gênero, Etnia, Classe: Estudos Multidisciplinares, grupo de pesquisas fundado em 1990, reunindo professoras de Serviço Social e das Ciências Humanas.

A criação do Núcleo de Pesquisa GECEM teve como objetivo reunir "pesquisadores, alunos de graduação e pós-graduação (mestrado e doutorado), na perspectiva de desenvolver projetos de pesquisa integrados, debates e eventos científicos diversificados, produzir material didático, realizar publicações conjuntas, produzir trabalhos acadêmicos (dissertações, teses, trabalhos de conclusão de curso de graduação, trabalhos de iniciação científica e outras monografias) e realizar assessorias em sua área temática. A reflexão acumulada neste Núcleo de Pesquisa permitiu dar visibilidade ao debate sobre Relações de Gênero e Direitos Humanos na Escola de Serviço Social. Certamente, não foi fortuita a inclusão de duas disciplinas sobre estes temas no novo currículo do Curso de Graduação.

Nesse momento, o debate sobre gênero, presente nos países anglosaxônicos desde a década de 1970, ainda não havia chegado ao Brasil, o que só ocorreu de forma mais expressiva a partir de 1990. Ademais, no Serviço Social, o tema era absolutamente marginal, diferentemente do que ocorria nas Ciências Humanas, em que houve a sua rápida incorporação pela Sociologia, Antropologia e História. A literatura, portanto, era incipiente, sobretudo, em se tratando do escopo de utilização em curso de graduação.

Com a nova reforma curricular, ocorrida em 2001, a introdução dessa disciplina não foi consensual. Para alguns, tratava-se de tema pósmoderno, como se o tema, por si só, definisse o que é próprio à modernidade ou à pós-modernidade. Interpreto essa visão, pouco explicitada em termos de debate acadêmico, como fruto, simultaneamente, de desinformação, desconhecimento da produção de docentes da própria unidade de ensino, preconceito e de, possivelmente, alguns ecos sobre a forma como se deu a incorporação do tema em certas áreas do conhecimento, como, por exemplo, a Linguística.

Não obstante, a disciplina, que passou a se chamar "Questão de Gênero no Brasil", tornou-se obrigatória e, desde o início, foi lecionada pela Professora Lilia Pougy, também pesquisadora do GECEM. Passei a partilhar com esta docente a disciplina "Direitos Humanos no Brasil",

${ }^{3} \mathrm{Na}$ nomenclatura atual: disciplina eletiva. 
também obrigatória e, pela primeira vez, incorporada à grade curricular de Serviço Social. Nesse momento, o estudo dos Direitos Humanos já fazia parte das minhas atividades intelectuais. Mas não só. Eu fazia regularmente a formação continuada de equipes interdisciplinares vinculadas a esse campo, assim como avaliações de programas e políticas sociais na área.

Nesse sentido, desde 1997, pesquiso modalidades de violência estatal, que representam graves violações dos direitos humanos, e as lutas derivadas também nesse campo. Na realidade, não troquei um tema pelo outro, mas passei a transitar entre os dois, ou melhor, ampliei o meu universo de inquietações intelectuais. Entendo a violência de gênero - linha de pesquisa à qual os projetos que desenvolvo desde 1986 estão vinculados como uma violação dos direitos humanos. Este campo temático, portanto, compreende e ultrapassa a violência de gênero. Cabe assinalar que, embora a defesa intransigente dos direitos humanos esteja inscrita no Código de Ética profissional como um dos princípios éticos fundamentais, a produção acadêmica do Serviço Social na área é residual, o que exige maior investimento para organização da bibliografia básica.

Em 2003, o livro organizado e publicado em conjunto com Maria Lídia Souza da Silveira e Victória Lavínia Grabois Olímpio, intitulado: "Violência estatal e experimentos de resistência na vida social brasileira", publicizou de forma mais ampla a participação de Vitoria no GECEM, membro também do Grupo Tortura Nunca Mais no Rio de Janeiro.

\section{Varandas Acadêmicas}

Esta me parece uma metáfora apropriada, uma vez que as varandas estão dentro dos espaços combinados, interiores, mas permitem olhar para fora e descobrir horizontes; são infinitamente menores do que os demais espaços, mas lhes dão amplitude, sobretudo aos contíguos, e permitem arejar e renovar o ambiente. Na minha trajetória acadêmica, construí duas varandas acadêmicas: a formação de equipes interdisciplinares e a avaliação de políticas públicas.

Os trabalhos voltados para a extensão através das atividades de assessoria e consultoria estiveram sempre presentes em sua trajetória, dentre os quais podem ser destacados: a elaboração do vídeo educativo Emília: a violência nossa de cada dia, debatido em cursos, seminários, treinamentos e grupos de reflexão, tendo sido apresentado, inclusive, em um Congresso Internacional na Finlândia, tendo sido legendado em francês; e a realização de um curso sobre "Relações de Gênero" para comandantes da Polícia Militar do Estado do Rio de Janeiro, realizado em parceria com o CEDIM Conselho Estadual dos Direitos da Mulher.

Suely participou de inúmeros processos de formação de equipes interdisciplinares, que implementam programas e políticas públicas nas 


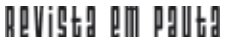

\} RECORTES DE INTENSAS TRAJETÓRIAS - MORGADO, R. \}

DOI: $10.12957 /$ REP.2016.27869

áreas de violência de gênero e direitos humanos, em vários Estados brasileiros, vinculadas a Centros de Apoio a Vítimas de Violência (atendem a várias modalidades de violência urbana, inclusive, a de gênero) e a programas congêneres. No Rio Grande do Sul, fiz também a formação de mulheres das periferias de Porto Alegre e de outros municípios que participam do "Programa de Formação de Promotoras Legais Populares". No Rio de Janeiro, fiz a formação da equipe do CIAM - Centro Integrado de Atendimento à Mulher, vinculado ao CEDIM - Conselho Estadual dos Direitos da Mulher; e participei da formação das equipes dos NIAMs Núcleos Integrados de Atendimento à Mulher, existentes em vários municípios do Rio de Janeiro. Faço também formação, da equipe do Centro de Referência de Mulheres da Maré. Desenvolvi, ainda de 1997 a 2001, a formação, em conjunto com a Professora Regina Benevides (UFF) e o Dr. Fernando Mattos, advogado do Gajop - Gabinete de Apoio Jurídico a organizações populares, de Pernambuco das equipes do "Programa de Proteção a Testemunhas e Vítimas Ameaçadas" (Provita).

Pude, através mais especificamente deste trabalho, me dar conta de que a categoria "desaparecimento" não se esgotou na ditadura, mas permanece em plena vigência da democracia. Ainda se desaparece no Brasil, como na Chacina de Acari, em que os corpos de 11 jovens jamais foram localizados. Mas também se desaparece para se continuar vivendo. Poucos sabem que ainda se vive com identidade clandestina no Brasil, como estratégia de sobrevivência, sem esperança de assumir a verdadeira identidade, com a mudança de regime, posto que a violência e a criminalidade estão por demais enraizadas na vida social.

No que tange à avaliação de políticas públicas, coordenei os processos de avaliação externa dos seguintes programas e projetos: "Projeto Cidadania e Direitos Humanos", em 2001; "Programa Nacional Paz nas Escolas", em 2002; "Projetos da área de Proteção dos Direitos da Criança e do Adolescente", em 2004; e "Programa Regional Piloto de Prevenção e Atenção à Violência Intrafamiliar contra a Mulher", em 2005.

As três primeiras avaliações referidas foram desenvolvidas em âmbito nacional, e a última teve dimensão estadual. Cada uma foi realizada com uma equipe diferente, utilizando metodologias diversificadas. O trabalho consistiu na elaboração do projeto de avaliação; implementação e coordenação do processo de avaliação; elaboração de relatório parcial, apresentado e discutido em seminário com as pessoas-chaves implicadas; e elaboração do relatório final, também apresentado e discutido em seminário, como momento de devolução dos resultados para as entidades avaliadas e os órgãos gestores. Todas as metodologias foram construídas em bases participativas, assegurando-se a discussão dos resultados com as entidades avaliadas, na medida em que entendo que o processo de avaliação não é unilateral e deve possibilitar implicações no desenvolvimento do trabalho posterior. 
Pudemos perceber que o país não dispõe de políticas públicas integradas nas áreas avaliadas; antes, existem aglomerados de programas e projetos, construídos, na maioria das vezes, sem níveis definidos de articulação, revelando grande fragmentação. Por essa razão, as avaliações foram formuladas também no sentido de indicar e sugerir caminhos possíveis para construção de políticas públicas universais.

Quando exerceu o mandato de Decana no CFCH/UFRJ organizou, em 2004, junto com Maria Lidia Souza da Silveira e Andreia Teixeira, o Seminário: 64 + 40 - Golpe e Campo(u)s de Resistência e em 2006, reestruturou o importante espaço de interlocução entre os pesquisadores do centro: Seminário de Integração Acadêmica do CFCH: Desafios às Ciências Humanas e Sociais.

Na área de interseção entre pesquisa, extensão e ensino, ressalto a importância de uma iniciativa no âmbito do Centro de Filosofia e Ciências Humanas. Trata-se da implantação do Centro de Referência de Mulheres, na Cidade Universitária - Ilha do Fundão ${ }^{4}$. Tem por objetivo: implantar um novo padrão de Centro de Referência para Mulheres no Brasil, contemplando as seguintes dimensões: desafio de construção da transdisciplinaridade, conjugando diversas áreas de conhecimento, das humanidades às áreas tecnológica e biomédica; atendimento integral às usuárias, com vistas à superação do quadro de violência de gênero, em suas variadas expressões, aliado à formação da consciência crítica da realidade brasileira e das múltiplas determinações das desigualdades sociais, numa perspectiva emancipatória; integração do trabalho de extensão universitária, com a produção de conhecimentos, por meio de pesquisas e estudos sistemáticos, e ensino; e constituição de um pólo permanente de debates sobre o tema, de articulação, avaliação e monitoramento de programas e políticas públicas na área da violência de gênero, de concepção e experimentação de metodologias inovadoras de intervenção e de formação continuada para a implementação desses programas e políticas. Considero que este Centro, alavancará pesquisas e produção de conhecimentos em violência, gênero e direitos humanos, e será um espaço de formação acadêmica de discentes e profissionais das diversas áreas de conhecimento.

Dessa forma, penso que venho realizando um trabalho coletivo, interdisciplinar, que tem, de fato, integrado pesquisa, ensino e extensão. Este vem sendo o solo a partir do qual se realiza minha produção acadêmica.

Sobre os principais aspectos teórico conceituais de sua produção, Suely ressalta:

Argumentava, já na dissertação de mestrado, que desvincular a condição feminina da condição de classe seria o mesmo que dizer que a

\footnotetext{
${ }^{4}$ O Acordo de Cooperação, firmado entre a UFRJ e a Secretaria Especial de Políticas para as Mulheres e a então Secretaria Especial dos Direitos Humanos da Presidência da República, foi aprovado nas instâncias acadêmicas pertinentes e tem o financiamento da Secretaria. O Centro está em funcionamento, desenvolvendo diversas atividades, articulando ensino, pesquisa e extensão.
} 


\section{peVistg all paltg}

\} RECORTES DE INTENSAS TRAJETÓRIAS - MORGADO, R. \}

DOI: $10.12957 /$ REP.2016.27869

categoria universal de sexo tem autonomia para operar mudanças no seu interior - análise presente em movimentos feministas pequeno-burgueses sem que passassem pela alteração das suas condições concretas de vida. Representaria, assim, entendimento duplamente equivocado: de um lado, que esta categoria, que permeia toda a sociedade e ultrapassa a sua divisão em classes, tem poder para transformar as estruturas sociais; de outro lado, que a libertação da mulher independe da luta por uma sociedade sem desigualdades, em que inexistam classes sociais antagônicas. No primeiro caso, tratar-se-ia de atribuir à categoria sexo o mesmo papel na história das classes sociais; no segundo, seria como ignorar as condições reais de existência de um amplo segmento da população feminina brasileira.

Sustentava, desde então, que o recrudescimento da violência nas relações conjugais, com a consequente agressão física, não configura um quadro patológico, mas se assenta nas assimetrias e hierarquias construídas e reproduzidas de forma ampliada, e solidamente enraizadas no senso comum, manifestando-se, sobretudo, quando a mulher esboça algum indício de recusa à submissão, tentando tornar as relações conjugais igualitárias.

Descrevi a escalada da violência, o seu processo de naturalização e a sua extensão a outros membros da família considerados igualmente tutelados. Analisei fatores considerados determinantes imediatos dessa forma de violência, que se alternam ou se combinam para justificar diferentes expressões de densas relações de poder.

Discuti a omissão da delegacia policial frente às situações apresentadas, mostrando o papel do policial como porta-voz, ao mesmo tempo, de uma cultura patriarcal e de um aparelho coercitivo, o que the confere duplo poder, levando-o a reforçar a violência - e contribuindo para a sobreviolência institucional - e a responsabilizar a mulher pela violência da qual é vítima.

Levantei a hipótese de que a criação de delegacias especializadas no atendimento à mulher pode atenuar a violência institucional; assinalava, no entanto, seu papel de apenas controlar os excessos da violência denunciada, deixando intocadas as raízes do fenômeno. Alertava, ainda, para o risco de reproduzirem o mesmo esquema de organização e funcionamento das delegacias distritais, se não fossem criadas políticas públicas efetivas das quais esses serviços fossem parte constitutiva.

Vislumbrava a importância do trabalho educativo desenvolvido pela Assistente Social, desde que estivesse consciente das raízes da opressão à mulher e vinculada a uma proposta de prática profissional, comprometida com um projeto de transformação social. Além de uma intervenção voltada para fortalecer a mulher na reivindicação dos seus direitos, assinalava a necessidade de favorecer o desencadeamento de um processo de reflexão com as vítimas de violência sobre a sua concepção de mundo e sobre determinações mais amplas do problema, de forma que pudesse acumular forças para recusar diferentes formas de dominação. 


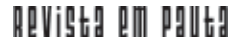

\} RECORTES DE INTENSAS TRAJETÓRIAS - MORGADO, R. \}

DOI: $10.12957 /$ REP.2016.27869

Largamente inspirada em Gramsci, realçava que autocriticar uma concepção de mundo permite desnudar contradições entre desejos e ações, ambivalências que permeiam os próprios desejos, sistematizar o que ainda é intuitivo e fragmentado. Enfatizava que este era o ponto de partida para a mulher desvendar a forma como estava organizando sua experiência de vida, para se apropriar dos seus medos, das suas inquietações e das suas esperanças. Na medida em que a concepção de mundo, as consciências não são individuais, mas refletem relações sociais diversas, pensar-se a si mesma significa pensar também e, sobretudo, essas relações; modificar-se a si mesma significa, da mesma forma, mudar a natureza dessas relações.

Considerava importante envolver os agressores nesse processo de agressão, de forma que as diferenças se explicitassem, fossem refletidas e enfrentadas, posto que, para serem criadas novas relações entre os sexos, seria preciso que as concepções de mundo dos homens também se transformassem em objeto de crítica e reelaboração. Registrava, entretanto, que se tratava de um nível mais complexo do trabalho, a ser desenvolvido em momento posterior, dada a necessidade de que aquela pessoa que viveu tanto tempo como um "ser para o outro" tivesse um espaço próprio de reflexão e decisão.

Estava delineado um conjunto de temas que viriam a se constituir para mim em objeto de reflexões nos anos que se seguiram: aprofundamento da análise sobre a produção e reprodução dessa modalidade de violência; o papel dos equipamentos sociais; e as possibilidades do trabalho social.

A ausência de aportes teóricos sobre relações de gênero e, mais particularmente, sobre violência de gênero levava-me à utilização da categoria inter-sexos e da alternância entre violência contra a mulher e violência conjugal, que representam, de fato, categorias descritivas, classificatórias, e não analíticas. Ainda assim, entendia que a produção da violência - e a sua superação - era indissociável do contexto das relações sociais, o que abria um veio de análise mais amplo.

O livro em colaboração com Heleieth Saffioti, Violência de gênero: poder e impotência é uma produção resultante de pesquisas que realizamos na ESS/UFRJ, vinculadas ao GECEM, a partir das quais foi produzido um extenso material empírico. Na menção que farei a esta produção, vou me ater às minhas contribuições.

Como o título indica, neste livro foi introduzido um conceito que viria a ser empregado amplamente: violência de gênero. Formulei-o, identificando as seguintes características: visa à preservação da organização social de gênero, fundada na hierarquia e desigualdade de "lugares sociais sexuados" que subalternizam o gênero feminino; amplia-se e reatualiza-se na proporção direta em que o poder masculino é ameaçado; é mesclada com outras paixões de caráter positivo, como jogos de sedução, afeto, desejo, esperança, que, em última instância, não visam a abolir a violência, mas a alimentá-la, como forma de mediatização de relações de exploração-domi- 


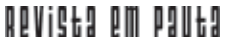

\} RECORTES DE INTENSAS TRAJETÓRIAS - MORGADO, R. \}

DOI: $10.12957 /$ REP.2016.27869

nação; denuncia a fragilizada auto-estima de ambos os cônjuges, que tendem a se negar reciprocamente o direito à autonomia nas mínimas ações.

Para a análise do quadro da violência de gênero denunciado, parti da seguinte questão: se a cultura da violência impregna as relações sociais, pode-se afirmar que as formas de violência perpetradas contra algumas categorias sociais - como o gênero feminino - é uma particularização da violência societária? Em outros termos, a violência doméstica está subsumida à violência em geral?

Respondo a essas questões, trabalhando a desconstrução de alguns mitos e evidenciando as particularidades dessa modalidade de violência. Refuto a existência de possíveis perfis de agressor e de vítima, discutindo como mulheres e homens participam da definição dos seus lugares e compactuam com a diferenciação e hierarquização de papéis que se constroem em múltiplos espaços societários; e, ao mesmo tempo, como lhes é possível romper este esquema estratificado e de sujeição.

Conquanto reconhecendo a importância de mudanças no plano jurídico-formal, em torno das quais vem se constituindo uma agenda feminista no Brasil e em outros países, discuto alguns dos seus limites, dentre os quais a concepção idealizada de que teriam como corolário transformações efetivas na realidade cotidiana das mulheres.

Afirmo que, se outras dimensões não forem também priorizadas, e as desigualdades forem reduzidas ao seu aspecto jurídico - sobretudo em um país no qual os direitos sociais são constantemente desrespeitados -, as contradições básicas da sociedade serão encobertas; a concepção de justiça, que abstrai a ordem legal e as instituições responsáveis por implementá-la dos processos e relações sociais que lhes são constitutivos, terminará por conferir à realidade uma visão estática e atomizada.

Outro marco na minha produção acadêmica foi o livro Femicídio: algemas (in)visíveis do público-privado, publicado em 1998, e que é uma versão reduzida da minha tese de doutorado. Com esta produção, como o título também sugere, introduzo no Brasil o conceito de femicídio, para evidenciar a não-acidentalidade da morte violenta de mulheres; e designar o caráter sexista dos crimes conjugais, desmascarando a aparente neutralidade dos termos homicídio e assassinato.

Como se pode perceber, trabalho também o conceito de campo de forças. Considero que, embora se possam isolar as relações de gênero para fins analíticos, não é possível abstraí-las do conjunto das outras relações igualmente fundamentais - as de classe e as étnico-raciais -, que vão sendo forjadas historicamente, configurando um campo de forças determinado. Neste, seus componentes são complementares e competitivos, determinam e sofrem ações dos sujeitos individuais e coletivos, que integram as forças em disputa em dada formação social. Tais ações traduzem-se em práticas materiais e simbólicas, metamorfoseáveis e negociáveis, a partir do permanente confronto de experiências. É também com base nesta tensão que são 


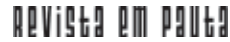

\} RECORTES DE INTENSAS TRAJETÓRIAS - MORGADO, R. \}

DOI: $10.12957 /$ REP.2016.27869

(re)construídos lugares sociais, que permitirão a reprodução/transformação das referidas estruturas e processos. Tem-se, portanto, uma processualidade irredutível a tão-somente um dos termos deste campo. Os sujeitos não apenas se situam em dado campo de forças, mas são constituídos por este, ao mesmo tempo em que o ressignificam.

O livro Violência de gênero e políticas públicas no Brasil, foi organizado por Suely e selecionado no Edital de Apoio a Livros Didáticos, da Fundação Universitária José Bonifácio foi publicado em 2007. O artigo de sua autoria, denominado "Essa violência mal-dita...", faz uma discussão conceitual da violência de gênero.

Argumento que a violência de gênero só se sustenta em um quadro de desigualdades de gênero. Estas integram o conjunto das desigualdades sociais estruturais, que se expressam no marco do processo de produção e reprodução das relações fundamentais - as de classe, étnico-raciais e de gênero. A estas relações podem-se agregar as geracionais, posto que não correspondem tão-somente à localização de indivíduos em determinados grupos etários, mas à localização do sujeito na história, na ambiência cultural de um dado período, na partilha ou na recusa dos seus valores dominantes, nas suas práticas de sociabilidade.

Sustento que a violência de gênero se passa num quadro de disputa pelo poder, o que significa que não é dirigida a seres, à partida, submissos, mas revela que o uso da força é necessário para manter a dominação, porquanto a ideologia patriarcal - tensionada por conquistas históricas, sobretudo feministas - não se revela suficientemente disciplinadora. A sua reprodução contínua, contudo, tende a acentuar a heteronomia, a fragilizar sobremaneira a auto-estima dos seus protagonistas, a provocar sintomas psicossomáticos e a levar à crescente passividade das suas vítimas. A passividade é, antes, consequência, e não causa, da violência de gênero institucionalizada.

Não se pode, no entanto, prescindir dessa ideologia, posto que as práticas autoritárias, coercitivas e punitivas, para que se mantenham, necessitam de uma base legitimadora, que faça supor o consentimento ativo do outro.

Defendo a concepção de que a violência de gênero, conquanto relacional, é construída em bases hierarquizadas, objetivando-se nas relações entre sujeitos que se inserem desigualmente nas estruturas familiar e societária. Assim, enquanto tendencialmente essas relações subjugarem a categoria feminina, a violência de gênero produzirá exponencialmente vítimas mulheres. Na medida em que homens e mulheres se apropriam e intervêm contraditoriamente nessas relações, em escala bastante reduzida, a violência de gênero pode também vitimizar homens.

Sobre sua trajetória destaca: Nesse longo período de docência, enfrentei desafios diferentes. Quando iniciei minhas atividades, a universidade estava polarizada pelo debate entre o autoritarismo e a demo- 


\section{Revistg aाm paltg}

\} RECORTES DE INTENSAS TRAJETÓRIAS - MORGADO, R. \}

DOI: $10.12957 /$ REP.2016.27869

cratização das relações pedagógicas. Paulo Freire havia denunciado a educação bancária, vertical, contrapondo-a à concepção da educação como um ato de libertação, de criação cultural. De fato, era necessário lutar para acabar com o autoritarismo reinante - e eu pude comprová-lo perfeitamente quando estudante - nas relações professor-aluno e nas práticas educativas em geral.

Precisei sair do Serviço Social e dialogar com outras áreas do conhecimento, para fazer um caminho de volta mantendo as janelas que abri. Precisei sair do país para desbravar outros territórios e voltar ao Brasil renovada, valorizando ainda mais a nossa cultura, a nossa natureza, os vínculos aqui deixados, e tendo uma percepção ainda mais crítica das nossas mazelas, das nossas desigualdades.

\section{Alguns destaques}

As preocupações teórico/políticas de Suely, não se restringiram, assim, a, de forma endógena, problematizar a violência de gênero. De minha perspectiva, Suely teve como marca intelectual a inquietude. Estruturou e desenvolveu projetos aos quais se dedicou com competência e determinação nos diferentes temas inetr-relacionados já citados anteriormente.

O GECEM consolidou-se, à época, como uma referência acadêmica na discussão de gênero e por mais de duas décadas, formou seguramente mais de uma centena de pesquisadores neste campo temático, dentre os quais tive o privilégio de fazer parte.

Entre 1999 - 2002 Suely foi diretora da Escola de Serviço Social/ UFRJ, sem nunca abrir mão de suas atribuições como docente ou pesquisadora. Em sua gestão, dentre tantas realizações, viabilizou em convênio com o Ministério da Justiça o "I Curso de Especialização em Direitos Humanos e Assistência a Vítimas e Testemunhas", destinado a profissionais do Programa de Assistência a Vítimas e Testemunhas Ameaçadas, oriundos de dez estados brasileiros.

Foi Decana do CFCH entre 2002- 2006 e além de dar sentido novamente ao próprio CCFH como instância intermediária na gestão acadêmico/administrativa da Universidade, desenvolveu entre outros projetos a estruturação do Núcleo de Estudos de Políticas Públicas em Direitos Humanos - NEPP - DH, que tem hoje seu nome em homenagem. O NEPPDH é um órgão suplementar do Centro de Filosofia e Ciências Humanas, foi inaugurado em 18 de dezembro de 2006 e constitui-se no primeiro Núcleo de Políticas Públicas em Direitos Humanos, com caráter estatutário, em universidade pública brasileira.

No campo teórico pensava o "campo de forças", tendo por referência pressupostos densos e um objetivo: contribuir para o fortalecimento 
de políticas públicas, em uma sociedade mais igualitária na perspectiva de gênero e, portanto, mais democrática, pensando também o papel do Serviço Social neste processo. Para isso todas as dimensões de sua trajetória profissional se entrecruzavam.

Estudou os mecanismos de produção e reprodução da violência de gênero, como "processo macro e micropolítico, que se desenvolve em escala societal e interpessoal. Analisar a constituição desse fenômeno como violência estrutural, vinculada às desigualdades estruturadas no conjunto complexo e contraditório de relações de gênero, classes e étnico-raciais".

Importante observar que, ainda hoje, são poucos os currículos de Serviço Social que têm disciplinas de gênero e/ou direitos humanos e que seu livro Femicídio, publicado em 1998, explicitou em seu título, o que se tornaria lei em nosso país somente em 2015 (Lei 13.104), com a nomenclatura de Feminicídio.

Suely faleceu em 2008, havia recém completado 52 anos.

\section{Principais publicações}

\section{Livros publicados/organizados ou edições}

- ALMEIDA, S. S.(org) Violência de gênero e políticas públicas. $1^{\text {a. }}$ ed. Rio de Janeiro: Editora da UFRJ, 2007. v. 1. 258p.

- ALMEIDA, S. S.; SOARES, B. M.; GASPARY, M. (Orgs.). Violência doméstica: bases para formulação de políticas públicas. $1^{\text {a. }}$ ed. Rio de Janeiro: REVINTER/FAPERJ, 2003. v. 1. 70p .

- ALMEIDA, S. S.; SILVEIRA, Maria Lidia Souza da (Org.) ; OLIMPIO, V. L. G. (Org.). Violência estatal e experimentos de resistência na vida social brasileira. $1^{\text {a. }}$ ed. Rio de Janeiro: FAPERJ / REVINTER, 2003. v. 1. 76p .

- ALMEIDA, S. S. Femicídio: algemas (in) visíveis do público-privado. $1^{\text {a. }}$ ed. Rio de Janeiro: Revinter, 1998. v. 1. 176p.

- SAFFIOTI, H.; ALMEIDA, S. S. Violência de gênero: poder e impotência.

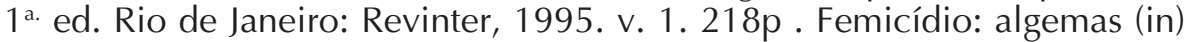
visíveis do público-privado

\section{Capítulos de livros publicados}

- ALMEIDA, S. S. Violência e subjetividade. In: RAUTER, C.; PASSOS, E; BENEVIDES, R.. (Org.). Clínica e Política: subjetividade e violação dos direitos humanos. $1^{\text {a. }}$ ed. Rio de Janeiro: Equipe Clínico-Grupal do Grupo Tortura Nunca Mais/RJ, Instituto Franco Basaglia/Editora Te Corá, 2002, v. 1, p. $45-50$. 


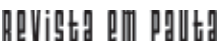

\} RECORTES DE INTENSAS TRAJETÓRIAS - MORGADO, R. \}

DOI: $10.12957 /$ REP.2016.27869

- ALMEIDA, S. S. Violência Urbana e Constituição de Sujeitos Políticos. In: Carlos Alberto M. Pereira et alli. (Org.). Linguagens da Violência. $1^{\text {a. }}$ ed. Rio de Janeiro: Rocco, 2000, v. 1, p. 97-112.

- ALMEIDA, S. S.. Políticas públicas e violência contra a mulher no Brasil. In: Martins, Alcina de C.; Henriquez, B.A. (Org.). Serviço Social no Feminino. Lisboa: 1997, v. , p. 27.

- SAFFIOTI, H. ; ALMEIDA, S. S. Brasil: violência, poder e impunidade. In: CAMACHO, Thimoteo. (Org.). Ensaios sobre violência. $1^{\text {a. }}$ ed. Vitória: EDUFES, 2003, v. 1, p. 85-114.

DOI: 10.12957/rep.2016.27869

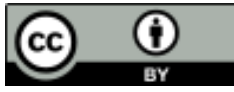

A Revista Em Pauta: Teoria Social e Realidade Contemporânea está licenciada com uma Licença Creative Commons Atribuição 4.0 Internacional. 